\title{
Subclinical hypothyroidism: to treat or not to treat?
}

Sivatharshya Pathmanathan ${ }^{1}$, Dharshini Karuppiah ${ }^{2}$

${ }^{1}$ Diabetes and Endocrinology unit, District General Hospital Kalutara.

2Diabetes and Endocrinology unit, Teaching Hospital Batticaloa.

Correspondence email: psivatharshya@gmail.com

ORCID ID: https://orcid.org/0000-0002-2510-3642

Copyright: This is an open-access article distributed under the terms of the Creative Commons Attribution License, which permits unrestricted use, distribution, and reproduction in any medium, provided the original author and source are credited (CC BY 4.0)

Prescribing levothyroxine has increased remarkably during the last decade, and these are mostly done for subclinical hypothyroidism. Subclinical hypothyroidism $(\mathrm{SH})$ is diagnosed when both serum-free thyroxine (FT4) and free triiodothyronine (FT3) are within the normal range, whereas the serum thyroid-stimulating hormone (TSH) is elevated (1). The prevalence of $\mathrm{SH}$ in the population varies between $4 \%$ and $20 \%$. Although $\mathrm{SH}$ is considered an asymptomatic disorder, some patients may present with non-specific symptoms, which can overlap with the symptoms of overt hypothyroidism $(\mathrm{OH})(2,3)$. In the US Colorado Thyroid Disease Prevalence Study, which included 20,862 subjects, patients with $\mathrm{SH}$ more frequently reported symptoms compared to euthyroid subjects but less frequently than patients with $\mathrm{OH}^{(2)}$. SH can progress to $\mathrm{OH}$ around $4 \%$ per year in the presence of Thyroid peroxidase antibodies, and $2 \%$ per year if antibodies are negative $(3,4)$.

As TSH screening is used widespread in primary care, it has increased the number of patients being diagnosed with $\mathrm{SH}$ (13). However, management of $\mathrm{SH}$ is still controversial, due to uncertainties related to the magnitude of its clinical benefit. A TSH cutoff level of $10 \mathrm{mIU} / \mathrm{L}$ is commonly used to distinguish between mild and more severe $\mathrm{SH}$ (4,5). Approximately $75 \%$ of patients with SH have a TSH level of less than $10 \mathrm{mlU} / \mathrm{L}(3,4,5)$. Current guidelines recommend that treatment is warranted when TSH $>10 \mathrm{mlU} / \mathrm{L}(5,6,7,9)$. In those with milder forms, treatment could be considered with levothyroxine in cases with repeated measures of elevated TSH, and symptoms compatible with hypothyroidism. On the other hand, some clinicians recommend that most patients with $\mathrm{SH}$ should be treated, including those with a serum TSH value below $10 \mathrm{mlU} / \mathrm{L}$ (14,15).

Those who favour treating $\mathrm{SH}$ prefer treating as some studies have shown that $\mathrm{SH}$ could be associated with increased risk of cardiovascular disease (CVD), mood disorders and cognitive dysfunction as well as impaired neuromuscular function $(3,4,7,8)$.

Patients with $\mathrm{SH}$ are believed to be at increased risk of atherosclerosis and disturbed blood coagulation. Thyroid hormones exert a direct influence on the heart and blood vessels and lipid status. (10,11,12). In $\mathrm{SH}$ there is a disruption of the systolic and diastolic function of the left ventricle. In the blood vessels, there are also changes in the form of increased vascular resistance, increased arterial stiffness and endothelial dysfunction. Many studies have shown that patients with $\mathrm{SH}$ have increased level of total cholesterol and low-density lipoprotein (LDL) compared to euthyroid patients (12). Despite these results, a clear connection between lipids and SH has not been established because some studies have shown that the lipid profiles of patients with $\mathrm{SH}$ were not significantly different compared to euthyroid patients (12). However, the lipid profile was more impaired in patients whose TSH is $>10 \mathrm{mlU} / \mathrm{L}$. Due to the extreme heterogeneity of the studies, we are unable to make any accurate conclusions about the influence of $\mathrm{SH}$ on $\mathrm{CV}$ system. Hence currently there is no evidence that a mild form of SH (TSH values are from 4.0 to $10.0 \mathrm{mlU} / \mathrm{L}$ ) may have consequences for patient's cardiovascular system. Similarly recent studies have shown that levothyroxine treatment in milder forms rarely affects cognition, mood, neuromuscular function, weight, or quality of life $(13,16)$.

Recent results from a large randomized clinical trial suggest that levothyroxine treatment doesn't benefit older adults with $\mathrm{SH}$. Serum TSH levels rise as people without thyroid disease age due to physiological adaptation. This phenomenon can led to an overestimation of the true prevalence of $\mathrm{SH}$ in persons older than 70 years $^{(15)}$. Therefore levothyroxine therapy may be associated with iatrogenic thyrotoxicosis, especially in elderly patients, and currently there is no evidence that it is beneficial in persons aged 70 years or older (15).

SCH should be treated in specific conditions, namely: pregnancy and infertility. Treatment with levothyroxine should be commenced in SH (TSH > $4.0 \mathrm{mlU} / \mathrm{L}$ ) in females planning pregnancy and if found during ongoing pregnancy, since normal thyroid function decreases the risk of miscarriage and other pregnancy complications. Nevertheless, before initiation of levothyroxine therapy in $\mathrm{SH}$, a repeated measurement of TSH level after 3 months is imperative. This is important, as a transient elevation of TSH levels that normalizes within 3 months has been reported in $60 \%$ of cases, and after 5 years in $62 \%$ of cases (15).

If a symptomatic response is not reached 3-4 months after TSH normalization, treatment should be stopped (4). This is invariably difficult, as hypothyroid symptoms are unspecific, and the decision to treat or not has to be individualized. 
Therefore until enough evidence become available each patient's thyroid function test should be assessed on an individual basis with the entire clinical picture in mind to decide whether to treat or not. Monitoring also needs to be vigilant, targets for treatment should be reassessed continually and treatment withdrawn if no favorable response is achieved after treating for considerable time. Similarly patients in whom treatment is deferred, periodic reassessment of TSH should be done to decide whether treatment needs to be initiated $(17)$.

\section{References:}

1. Robin P. Peeters. Subclinical Hypothyroidism New England Journal of Medicine 2017; 376:2556-65.

2. Canaris GJ, Manowitz NR, Mayor G, Ridgway EC. The Colorado thyroid disease prevalence study. Arch Intern Med. 2000;160:526-34

3. Vanderpump, M.P.; Tunbridge, W.M.; French, J.M.; Appleton, D.; Bates, D.; Clark, F.; Grimley Evans, J.Hasan, D.M.; Rodgers, H.; Tunbridge, F.; et al. The incidence of thyroid disorders in the community: A twenty-year follow-up of the whickham survey. Clinical Endocrinology 1995;43:55-68.

4. Kabadi UM. "Subclinical hypothyroidism". Natural course of the syndrome during a prolonged follow-up study. Arch Intern Med. 1993;153(8):957-61.

5. Surks MI, Ortiz E, Daniels GH, et al. Subclinical thyroid disease: scientific review and guidelines for diagnosis and management. JAMA 2004; 291: 228-38.

6. Jonklaas, J.; Bianco, A.C.; Bauer, A.J.; Burman, K.D.; Cappola, A.R.; Celi, F.S.; Cooper, D.S.; Kim, B.W. Peeters, R.P.; Rosenthal, M.S.; et al. Guidelines for the treatment of hypothyroidism: Prepared by the American thyroid association task force on thyroid hormone replacement. Thyroid 2014; 24; 1670-1751.

7. Garber, J.R.; Cobin, R.H.; Gharib, H.; Hennessey, J.V.; Klein, I.; Mechanick, J.I.; Pessah-Pollack, R.; Singer, P.A.;Woeber, K.A.; American Association of Clinical Endocrinologists; et al. Clinical practice guidelines for hypothyroidism in adults: Cosponsored by the american association of clinical endocrinologists and the american thyroid association. Endocrine Practise 2012; 18: 988-1028.

8. Pearce, S.H.; Brabant, G.; Duntas, L.H.; Monzani, F.; Peeters, R.P.; Razvi, S.; Wemeau, J.L. 2013 eta guideline: Management of subclinical hypothyroidism. Eur. Thyroid J 2013; 2: 215-228.

9. Okosieme, O.; Gilbert, J.; Abraham, P.; Boelaert, K.; Dayan, C.; Gurnell, M.; Leese, G.; McCabe, C.; Perros, P.;Smith, V.; et al. Management of primary hypothyroidism: Statement by the british thyroid association executive committee. Clin. Endocrinol. 2016; 84: 799-808.

10. Klein I, Ojamaa K. Thyroid hormone and cardiovascular System. N Engl J Med. 2001;344:501-9.

11. Rodondi N, Aujesky D, Vittinghoff E, Cornuz J, Bauer D. Subclinical hypothyroidism and the risk of coronary heart disease:a meta-analysis. Arch Intern Med. 2005;165:2460-66

12. Caraccio N, Ferrannini E, Monzani F. Lipoprotein profile in subclinical hypothyroidism:response to levothyroxine replacement, a randomized placebo-controlled study. J Clin Endocrinol Metab. 2002;87:1533-38.

13. Jan Calissendor,Henrik Falhammar. To Treat or Not to Treat Subclinical Hypothyroidism, What Is the Evidence? Medicina 2020;56: 40 ; doi:10.3390/medicina56010040.

14. Jonklaas, J.; Razvi, S. Reference intervals in the diagnosis of thyroid dysfunction: Treating patients not numbers. Lancet Diabetes Endocrinol. 2019; 7: 473-483.

15. Stott, D.J.; Rodondi, N.; Kearney, P.M.; Ford, I.;Westendorp, R.G.J.; Mooijaart, S.P.; Sattar, N.; Aubert, C.E.;Aujesky, D.; Bauer, D.C.; et al. Thyroid hormone therapy for older adults with subclinical hypothyroidism.N. Engl. J. Med. 2017; 376: 2534-44.

16. Feller M, Snel M, Moutzouri E et al. Association of thyroid hormone therapy with quality of life and thyroid-related symptoms in patients with subclinical hypothyroidism: a systematic review and meta-analysis. $J A M A$. 2018; 320: 13491359.

17. N P Somasundaram, M Sumanatilleke, P Katulanda, et al. Thyroid Disorders - Clinical Practice Guidelines. Sri Lanka J Diabetes Endocrinol Metab. 2020; 10(1):41-85. 